\title{
Emotional Intelligence and Educational Robotics: The Development of the EI-EDUROBOT
}

\author{
Dimitrios Ziouzios, Michalis Ioannou, Ioanna Tsolopani, Tharrenos Bratitsis, and Minas Dasygenis
}

\begin{abstract}
In recent years, ICT has become a fundamental element of almost all aspects of formal and non-formal education. Educational Robotics (ER) as an ICT subfield has triggered many studies of ER educational utilization. Furthermore, there is also a growing interest in studies in Special Education with ER and ICT in general, usually focusing on emotional intelligence, especially in social skills' development and empathy training. This paper presents the development of a Robotic Platform, the EI-EDUROBOT, which aims to cultivate empathy and social skills of typically developed children, aged 4 to 9 years, but also children with Autism Spectrum Disorders (ASD), among these two social groups.
\end{abstract}

Index Terms-Autism, Early Childhood Education, Educational Robotics, Empathy, Preschool ages

\section{INTRODUCTION}

Over the last decades, Information and Communication Technologies (ICT) in Education attract research interest on a global scale. In recent years, this interest has been growing focusing on the effective use of ICT in the learning process both in the fields of formal/typical and in special education. In the age of digital literacy, innovative technological instruments and tools are increasingly available for research within the learning process.

Educational Robotics (ER) is used in the classrooms and teachers from all levels of education utilize ER to present novel topics to their students. It is an innovative teaching approach that uses programmable systems and it is grounded on project-based learning. It is identified by the use of ICT in the context of their abilities for observation, analysis, modeling, and control of various physical tasks [6]. In addition, ER offers opportunities both to educators and children to study STEAM (Science, Technology, Engineering, Arts, Mathematics) fields and other subjects, such as literacy, through teamwork, problem-solving, and cultivating collaboration skills and critical thinking [8].

At the same time, researchers' interest is growing about the role of ICT in the modern school and particular in their contribution to the therapeutic interventions for students with special educational needs [25]. Researchers point out the exciting learning experience that ER can offer to these students [5],[12].

Published on December 19, 2020

Dimitrios Ziouzios, Department of Electrical and Computer Engineering, University of Western Macedonia.

(e-mail: dziouzios@uowm.gr)

Michalis Ioannou, Department of Early Childhood Education, University of Western Macedonia.

(e-mail: mioannou@uowm.gr)

Tsolopani Ioanna, Department of Early Childhood Education, University of Western Macedonia.
The present paper presents the EI-EDUROBOT (Emotional Intelligence Educational Robot), an innovative Educational Robotics product, that aims to develop Emotional Intelligence for children 4 to 9 years old with typical development and children with special educational needs, emphasizing in Empathy. The paper is structured as follows: firstly, the theoretical framework is presented. Then, the EI-EDUROBOT Platform's Needs Analysis and Technical Specifications are described, followed by a conclusion.

\section{THEORETICAL FRAMEWORK}

\section{A. Educational robotics}

ER appeared in the 1980's, in the context of using ICT in the educational process, mainly through the pedagogical trend of Logo. ER makes extensive use of the principles of artificial intelligence [14]. In general, it refers to the teaching practice in which students use a robot, usually with the guidance of a teacher, either to develop new knowledge using them or to gain knowledge about the robot itself [19].

There are two categories of ER. The first refers to constructing and manipulating a robot. The second requires programming a robot to solve a problem and make decisions that determine its behavior [13]. The main ER tool is the programmable robot. Thus, ER can be considered as an important instrument for students to build learning experiences [1]. It is related to both the observation and simple handling of a robot as well as more demanding tasks as the students are involved in planning, problem-solving and decision making in relation to the robot's behavior, with the aim of developing creative thinking, the highest level of thinking [3].

The pedagogical objectives of ER are based on two main arguments. The first is based on the preparatory role of school education and concerns ER as a subject of study while the second derives from the pedagogical dimension of education and treats ER as a learning tool [9]. In Early Childhood and low Primary Education settings, a sub-category of ER is mainly used, the Logo-like programmable toys, such as Beebot, Bluebot, and Probot (known also as floor roamers). These are controlled by the user, who designs and determines the commands that the robot is required to execute. This way, children's metacognitive abilities are enhanced as they reflect

(e-mail: itsolopani@uowm.gr)

Tharrenos Bratitsis, Department of Early Childhood Education, University of Western Macedonia

(e-mail: bratitsis@uowm.gr)

Minas Dasygenis, Department of Electrical and Computer Engineering, University of Western Macedonia.

(e-mail: mdasyg@ieee.org) 
on the thinking process that they have followed. Also, problem-solving and spatial orientation abilities are promoted [19].

In addition, ER can serve as a means of integration for students with learning and other disabilities. All students should involve themselves in practical science and technology environments to prepare applying corresponding knowledge in real-world settings [7].

\section{B. Educational Robotics and Special Education}

ICT is a powerful toolkit for teachers. Research highlights the promising results of ICT use in special education [4], [14], [16], [18]. However, most of the research in the field concerns people with Autism Spectrum Disorder deficiencies (ASD), as they interact more effectively with technological products (e.g. robots) than with humans [22].

ER for students with special educational needs includes the use of social robots for teaching various skills such as cognitive function, communication, and collaborative play [15]. People with ASD are unable to maintain eye contact with their teacher or peers [12]. In these cases, a humanoid robot can offer a point of interaction for developing social skills that can be transferred to the real world in the future [21].

It seems that interaction with a robot for a short period time (five sessions) can reduce stereotypical autistic behaviors [26] when an individual interacts with the robot in a children's free play session under the supervision of a teacher [12]. Additionally, humanoid robots have been proposed as ideal social mediators that encourage the involvement of students who face difficulties in developing social skills [24]. Also, there are non-humanoid robots that usually have animal or cartoon forms. According to Sartorato, Przybylowski and Sarko [23], greater attention and involvement of children with ASD was observed during the learning process and their interaction with non-humanoid robots.

\section{Empathy}

Empathy is a complex construct and specific social cognitive ability related to taking part in the suffering of others [11]. It includes a cognitive dimension which involves the capability to see things from the perspective of others and an affective dimension related to sharing other people's emotions [20].

Empathy is a significant issue for special education, in two essential directions. The first regards students with special needs themselves who appear to have a deficiency in social perception and cognition, subtle impairment of verbal and non-verbal communication, presence of idiosyncratic isolated interests, and repetitive behaviors [2]. The second direction regards the social behavior of others towards individuals with such deficiencies. Since anything that differs from what is considered as "normal" usually leads to marginalization, these individuals often reach the point of social withdrawal. Thus, children with insufficient mastering of social skills do not communicate and relate to others efficiently while they experience problems in playing, working, and learning with peers, which may well result in a certain degree of isolation [10].

\section{EI-EDUROBOT PLATFORM}

\section{A. Needs Analysis}

The EI-EDUROBOT (Figure 1) in an open-source training robot that can be used by both children aged 4 to 9 to learn by playing as well as older users, who can program and create their own scripts. The innovation of EI-EDUROBOT is that it can be used by children who have mainly autism spectrum disorders, mainly deficient social skills. In addition, the robot incorporates a mode that allows it to simulate the actions of an autistic child. Using this mode, children can be taught how to interact with a child with ASD deficiencies. Also, teachers can use this robot for STEAM education (Science, Technology, Engineering, Arts, and Mathematics).

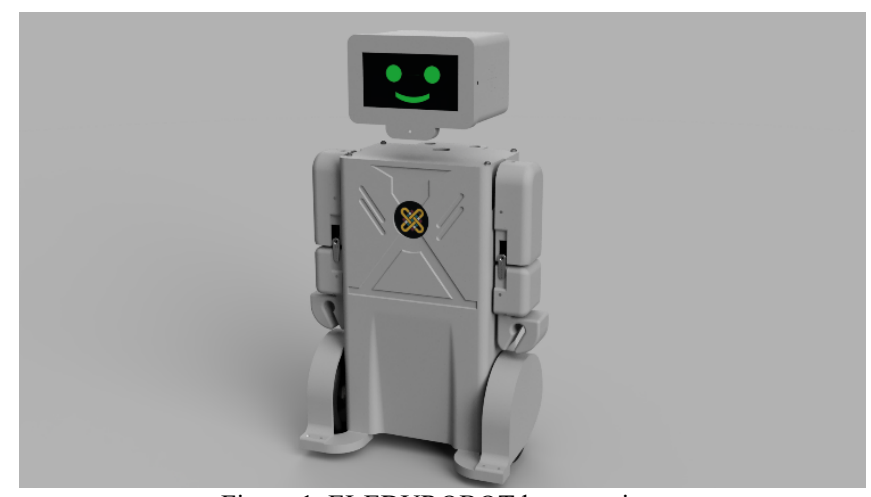

Figure 1. EI-EDUROBOT beta version

To achieve all the aforementioned, several sensors need to be integrated into the robot, along with a user-friendly programming language and management platform. The sensors are mainly divided into two categories: a) safetyrelated sensors, and b) the education-related sensors. The EIEDUROBOT is addressing children and special attention has been paid to reassuring both their and its safety. The integrated sensors are explained in the next section.

Also, the EI-EDUROBOT is based on open-source software (OSS), allowing other users the rights to study, change, and distribute the software to anyone and for any purpose [17].

\section{B. Technical Specifications}

The EI-EDUROBOT educational platform consists of three main pillars: 1) hardware, 2) software, and 3) the management platform - mobile app.

\section{1) Hardware}

The basis of the robot is a raspberry pi 4 (https://www.raspberrypi.org/) model B which offers a highperformance 64-bit quad-core processor, dual-display support at resolutions up to $4 \mathrm{~K}$ via a pair of micro-HDMI ports, hardware video decode at up to $4 \mathrm{Kp} 60$, up to $4 \mathrm{~GB}$ of RAM, dual-band 2.4/5.0 GHz wireless LAN, Bluetooth 5.0, Gigabit Ethernet, USB 3.0 and Power over Ethernet (PoE) capability. These specifications cover the needs of the project and the low cost and the low energy consumption make it cost-efficient.

It is equipped with a 7" touchscreen monitor and the screen resolution is $800 \times 480$ pixels. The touchscreen is the face of EI-EDUROBOT. Also, it has a camera with 8-megapixel native resolution, uses the Sony IMX219PQ image sensor high-speed video imaging and high sensitivity, sensor- 
capable of $3280 \times 2464$ pixel static images and supports 1080p30, 720p60, and 640x480p90 video. This camera perfectly matches the raspberry pi and the specifications are ideal for the scripts that the robot will perform. The sound of high importance for the designed scenarios, thus a highquality stereo speaker is installed. Moreover, for the robot to be interactive it should be able to respond to environmental sounds. The EI-EDUROBOT has an electret microphone amplifier which has excellent power supply noise rejection, includes a trimmer pot to adjust the gain and is best used for projects such as voice changers, audio recording/sampling, and audio-reactive projects.

The EI-EDUROBOT also integrates a variety of sensors. At the top of the head, it has a membrane potentiometer. It is very thin and by pressing down on various parts of the strip, the resistance linearly changes from 100 to 10.000 Ohms. This allows to accurately calculate the pressure position on the strip. This is very important because the robot can feel the touch on the head and may react accordingly to the pressure. On the shoulders, digital touch sensors have been installed; they are capacitive touch switches that detect when a finger touches the corresponding position. Then the module value is set to high and a script is executed. If not touched for 12 seconds then it is switched off to low-power mode. Moreover, the EI_EDUROOT has three IR Line Track Follower Sensor Obstacle Avoidance Modules which allow it to not fall when placed for example on a table. It has high sensitivity with stable performance, strong anti-interference ability, and the detection distance is about $10 \mathrm{~mm}$. The IR Sensors are constantly sending signals and receive a portion back, depending on the reflection surface. When the signal is lost, the robot stops as it identifies a gap. The last sensor is the ultrasonic one which is used both for educational purposes and for security reasons. The Ultrasonic sensor emits ultrasound at $40000 \mathrm{~Hz}$ which travels through the air and if there is an object or obstacle on its path it will bounce back to the module. Considering the travel time and the speed of the sound the distance covered can be calculated.

The moves that EI-EDUROBOT can perform are five: i) moving the head left and right ii) moving the head up and down, iii) moving the arms from the shoulders up and down, iv) moving the elbows, v) move forward, backward and steering. Because it needs 8 motors and the pins of the raspberry pi are limited, a 16Ch 12-bit PWM Servo Shield Motor Driver I2C Module is installed to handle all of them. Two powerful stepper motors are used for moving the robot which has three wheels; two for steering and moving forward/ backward and another one for balance.

The EI-EDUROBOT has been printed in a 3D printer using NEEMA 3D PLA filaments. After the final version, the designs will be freely available to everybody for nonprofit operations, maintaining the proper references, the creators name and the robot's name.

\section{2) Software}

Raspberry pi is running a Linux based Operating System (OS), Raspbian which is a free operating system based on Debian and it is optimized for the Raspberry Pi hardware. To control the robot and use all its capabilities, a powerful and fast programming language was used, Python (https://www.python.org/). At this point, two modes and four scenarios in python have been developed, and external users can design and program their own scenarios to upload them via the management platform to the robot.

\section{3) Management Platform - Mobile App}

The connection between the hardware and software has been established by a powerful web-based Management Platform (MP). Every user must register the robot to the MP entering the serial number and personal data. The MP was developed by using Node.js (https://nodejs.org/), an opensource server environment built on Chrome's JavaScript runtime and designed to build scalable network applications. It is efficient for data-intensive real-time applications that run across distributed devices. The framework interface is user friendly and based on W3C standards: accessibility, usability, and inclusion that works for everyone. It has a clear structure, easy navigation, simple forms, and it has a responsive and compatible design. Users with slow connection speed or low bandwidth can have instant access.

Through the MP the user can handle the robot. Four scenarios have been developed and pre-installed on the EIEDUROBOT, for the potential user to choose. Everyone with basic knowledge of python can write a scenario and upload it via MP to the robot. After being uploaded to the robot, a scenario can be executed by just the corresponding name from a dropdown menu. Future plans include the provision of a free block-based visual programming language for users to easily develop scenarios.

Moreover, the MP is giving live access to the robot's camera and microphone. The user can talk through a microphone, watch through the robot's camera and handle the moves of the robot in real-time. This mode is very useful for users without any programming knowledge or for special educational programs. It is very easy to use and challenges the creativity of the user.

The MP is completed by a mobile application. Using an Application Programming Interface (API) which is entirely customizable and defines interactions between the MP and the mobile application, the user can handle most of the MP functions.

\section{CONCLUSION}

The EI-EDUROBOT has been designed to be used by children with ASD deficiencies to enhance their social skills, as it is programmed to interact as a human with them. Additionally, it will likewise interact with children of typical development, simulating the behavior of a child with ASD deficiencies. Overall, the aim is empathy cultivation for both population types for each other. Utilizing the integrated sensors and preloaded scenarios, such simulations are feasible, under the supervision of an adult. The aim is to treat conditions that are under-researched and usually evolve in inclusive classrooms, especially at young ages. There are the main innovations of this robot compared to the abovementioned robots.

In addition, The EI-EDUROBOT aims to be a costefficient, compared to other robots (e.g. NAO), and easy to use. It also has more movement capabilities and more sensors than other robots (Beebot, Bluebot, etc.). It consists of lowcost parts and the main advantage is that it is built on opensource platforms so that every user can program it and upload new scenarios and scripts. The instructions for replicating and programing the EI-EDUROBOT will be freely available. It is also planned to develop a visual programming interface to further facilitate teachers with little or no programming experience to utilize the EI-EDUROBOT. The combination 
of these aforementioned features makes it a unique type of robot for educational purposes in General and Special Education.

Future research focuses on the educational utilization of the robot in special education through the development of training scenarios by the research team and primary education teachers. EI-EDUROBOT will also be used for STEAM education.

Finally, experimental interventions are designed and planned to be implemented in the 2020-2021 school year in order to assess the EI-EDUROBOT and evaluate the overall educational approach with the robot mainly for empathy training, but also for STEAM activities.

\section{ACKNOWLEDGMENT}

This research has been implemented in the framework of the Action "Business Enhancement for Research projects" and co-financed by the European Union and national resources through the B.P. WESTERN GREECE 2014-2020 (project code: DEP5 - 0019433)

\section{REFERENCES}

[1] Alimisis, D. (2013). Educational robotics: Open questions and new challenges. Themes in Science \& Technology Education, 6(1), 63-71.

[2] APA. 2013. Diagnostic and statistical manual of mental disorders 5th ed. Washington, DC: American Psychiatric Association.

[3] Belesiotis, V., \& Kokkinos, S. (2012). Educational robotics and Arduino. 4th Conference on Informatics in Education, 493-501.

[4] Chen, W. (2012). Multitouch tabletop technology for people with autism spectrum disorder: A review of the literature. Procedia Computer Science, 14, 198-207.

[5] Conti, D., Di Nuovo, S., Buono, S., \& Di Nuovo, A. (2017). Robots in education and care of children with developmental disabilities:a study on acceptance by experienced and future professionals. International Journal of Social Robotics, 9(1), 51-62.

[6] Depover, C., Karsenti, T. \& Kó $\eta_{\varsigma}$, B. (2010). Teaching using Technology. Athens: Kleidarithmos.

[7] Dorsey. R, Park C.H, Howard A.M. (2013). Developing the Capabilities of Blind and Visually Impaired Youth to Build and Program Robots. Annual Int. Technology and Persons with Disabilities Conference, San Diego, CA.

[8] Eguchi,A. (2014). Robotics as a Learning Tool for Educational Transformation. Proceedings of 4th International Workshop Teaching Robotics, Teaching with Robotics \& 5th International Conference Robotics in Education.

[9] Fragou, S. (2009). Educational Robotics: Pedagogical Framework and Methodology of interdisciplinary project based learning. In Gregoriadou, M., Gogolou, A., Gouli, E, Glezou, K., Tsaganou, G, Kanidis, E., Doukakis, D., Fragou, S., \& Verginis, E. (Eds.), Teaching Approaches and Tools for Teaching Informatics, pp. 474-490. Athens: New Technology Publications.

[10] Frostad, P., Pijl, SJ. 2006. Does being friendly help in making friends? The relation between the social position and social skills of pupils with special needs in mainstream education. European Journal of Special Needs Education, 22, 1 (Dec. 2006), 15-30. DOI= http://dx.doi.org/10.1080/08856250601082224

[11] Hoffman, ML. 2000. Empathy and moral development: Implications for caring and justice. Cambridge. UK: Cambridge University Press.

[12] Hughes-Roberts, T., Brown, D., Standen, P., Desideri, L., Negrini, M., Rouame, A., Wager, G. \& Hasson, C. (2018). Examining engagement and achievement in learners with individual needs through roboticbased teaching sessions. British Journal of Educational Technology, $50(5)$.

[13] Kokkori, A. \& Valiatza, B. (2013). Approach of educational robotics through the Hydro-Robot. 7th Panhellenic Conference of Informatics Teachers "Informatics in Primary and Secondary Education Challenges and Prospects", Thessaloniki.

[14] Komis, V. (2004). Introduction to ICT Educational Applications. Athens: New Technologies Publications.

[15] Krägeloh, C. U., Bharatharaj, J., Kutty, S., Kumar, S., Nirmala, P. R., \& Huang, L. (2019). Questionnaires to Measure Acceptability of Social Robots: A Critical Review. Robotics, 8(4), 88.
[16] Kuenzi, J. (2008). Science, technology, engineering, and mathematics (STEM) education: Background, federal policy, and legislative action. Congressional research service reports. Available at http://digitalcommons.unl.edu/crsdocs/35.

[17] Laurent, St., and Andrew, M. (2008). Understanding Open Source and Free Software Licensing. O'Reilly Media.

[18] Mazon, C., Sauzeon, H. \& Fage, C. (2018). Effectiveness and usability of technology-based interventions for children and adolescents with ASD: A systematic review of reliability, consistency, generalization and durability related to the effects of intervention. Computers in Human Behavior, 93, 235-251.

[19] Misirli, A. \& Komis, V. (2014). Robotics and Programming Concepts in Early Childhood Education: A Conceptual Framework for Designing Educational Scenarios. In: Karagiannidis C., Politis P., Karasavvidis I. (eds) Research on e-Learning and ICT in Education, pp 99-118. Springer, New York, NY.

[20] Ornaghi, V., Brockmeier, J., Grazzani, I. 2013. Enhancing social cognition by training children in emotion understanding: A primary school study. Journal of Experimental Child Psychology. 119 (Nov. 2013), 26-39. DOI= http://dx.doi.org/10.1016/j.jecp.2013.10.005

[21] Owens, G., Granader, Y., Humphrey, A. \& Baron-Cohen, S. (2008). LEGO ${ }^{\circledR}$ therapy and the social use of language programme: An evaluation of two social skills interventions for children with high functioning autism and Asperger syndrome. Journal of Autism and Developmental Disorders, 38(10), 1944.

[22] Pennisi, P., Tonacci, A., Tartarisco, G., Billeci, L., Ruta, L., Gangemi, S. \& Pioggia, G. (2016). Autism and social robotics: A systematic review. Autism Research, 9(2), 165-183.

[23] Sartorato, F., Przybylowski, L., \& Sarko, D. K. (2017). Improving therapeutic outcomes in autism spectrum disorders: Enhancing social communication and sensory processing through the use of interactive robots. Journal of psychiatric research, 90, 1-11.

[24] Standen, P., Brown, D., Roscoe, J., Hedgecock, J., Stewart, D., Trigo, M. J. G., \& Elgajiji, E. (2014). Engaging students with profound and multiple disabilities using humanoid robots. In International Conference on Universal Access in Human-Computer Interaction, pp. 419-430. Springer International Publishing.

[25] Tsiopela, D. \& Tzimogiannis, A. (2018). ICT in Education of people with Autism Spectrum Disorders: Literature Ovierview. Themes in Science and Technology Education, 10(1), 19-35.

[26] Werry, I., \& Dautenhahn, K. (1999). Applying mobile robot technology to the rehabilitation of autistic children. In Proceedings SIRS99, 7th International Symposium on Intelligent Robotic Systems, pp. 265-272.

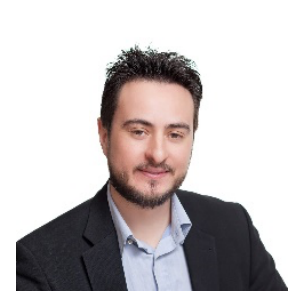

Dimitrios Ziouzios is a PhD Candidate at the Department of Electrical and Computer Engineering, University of Western Macedonia. He holds MSc in "Business Information Technology". His main research interests include Embedded System, Robotics, Accelerators and Computer Architecture. His interests also include the use of embedded system in pollution and environmental technologies.

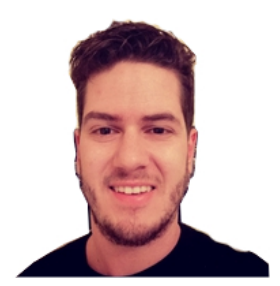

Michalis Ioannou is a $\mathrm{PhD}$ Candidate at the Department of Early Childhood Education, University of Western Macedonia. He holds MSc MSc in "Educational Sciences: Science, Environment and Technology in Education" and a bachelor's degree in Early Childhood Education. His main research interests include STEAM Education, Science Didactics, Educational Sciences and Educational

Robotics.

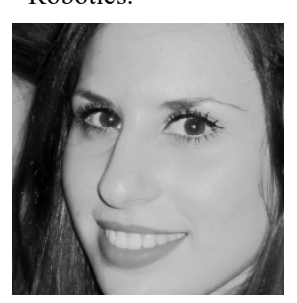

Ioanna Tsolopani is a $\mathrm{PhD}$ Candidate at the Department of Early Childhood Education, University of Western Macedonia. She holds a MSc in Didactic Methodology and Curricula (2016), a MSc In Special Education (2018) and a Bachelor's degree in Early Childhood Education (2012). She has worked as a teacher in Parallel Support Programme. Her interests focus on ICTs in education, special education, collaborative narrative coaching and STEAM. 


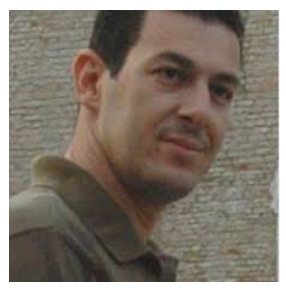

Tharrenos Bratitsis is an Associate Professor of Informatics, at the Department of Early Childhood Education, University of Western Macedonia. During the last years, he works intensively on CSCL, digital storytelling, technology \& art-based learning approaches, game-based learning and innovative teaching approaches, including STEAM. He has participated in over 200 international conferences as a member of the scientific committee, is a reviewer for 45 scientific journals and publishes regularly, having about 200 scientific papers, 1 book \& 4 edited volumes.

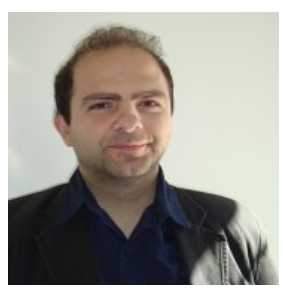

Minas Dasygenis is an Assistant Professor at the Department of Electrical and Computer Engineering, University of Western Macedonia. He teaches Operating Systems, Computer Architecture, Embedded Systems, Parallel \& Distributed Systems. His interests focus on robotics, embedded and cyberphysical systems, gamification, Internet of Things, security and hardware \& software cosynthesis. He has been a PC member for various conferences, published over 70 scientific papers and authored 3 books. 